\title{
RESEARCH ON THE CRUSTAL DEFORMATION CHARACTERISTICS IN BEIJING USING INSAR AND GNSS TECHNOLOGY
}

\author{
Leyin $\mathrm{Hu}^{1}$, Chengqi Xing ${ }^{1}$, Keren $\mathrm{Dai}^{2,3}$, Yongsheng $\mathrm{Li}^{4}$, Zhenhong $\mathrm{Li}^{5}$, Jingfa Zhang ${ }^{3}$ \\ Rui $\mathrm{Yan}^{1}$, Bin $\mathrm{Xu}^{1}$, Zhiyong Fan ${ }^{1}$
}

\begin{abstract}
${ }^{1}$ Beijing Earthquake Agency, China-huleyin@hotmail.com, (xingcq, yanrui, xubin, fanzhiyong) @bjseis.gov.cn ${ }^{2}$ College of Earth Sciences, Chengdu University of Technology, Chengdu 610059, China - daikeren17@cdut.edu.cn ${ }^{3}$ State Key Laboratory of Geohazard Prevention and Geoenviroment Protection, Chengdu University of Technology, China ${ }^{4}$ Key Laboratory of Crustal Dynamics, Institute of Crustal Dynamics, CEA, China-whlys@163.com, zhangjingfa@hotmail.com ${ }^{5}$ School of Civil Engineering and Geosciences, Newcastle University, UK-Zhenhong.Li@newcastle.ac.uk
\end{abstract}

\section{Commission III, WG III /3}

KEY WORDS: Beijing, INSAR, GNSS, Crustal Deformation, Geological structure

\begin{abstract}
:
In this paper, we tried to reveal the characteristics of the crustal deformation in both the horizontal and vertical directions in Beijing using InSAR and GNSS observations. Regarding the serious land subsidence in Beijing plain, we also analysed the mechanism of the occurrence and development of the subsidence in combination with the tectonic settings. The GNSS results reveal that the crust in Beijing shows a significant left-lateral trend movement in the horizontal direction, while the vertical direction shows a gentle rise in the mountainous region and a significant subsidence in the plain area. The INSAR results shows a detailed subsidence area and the deformation characteristics were analyzed considering the fault activity. The foundation of geological structure dominates the subsiding in the Beijing Plain. The exploitation of groundwater exacerbates the level of subsidence and has new development. The active faults controlled the development of the subsiding in present days.
\end{abstract}

\section{INTRODUCTION}

Beijing, as the capital of China, has taken on important functions of political, cultural, international exchanges and technological innovation centers. At the same time, Beijing is located at the juncture of the two large blocks in the fault depression zone of the North China Plain and the uplift block of the YanshanTaihang-Inner Mongolia Plateau, located at the junction of the North China Plain, Shanxi Seismic Zone and Zhangjiakou-Bohai Sea seismic zone. There are plenty of active faults, active blocks, active basins, quaternary implicit depressions and diverse landform types (Figure 1).

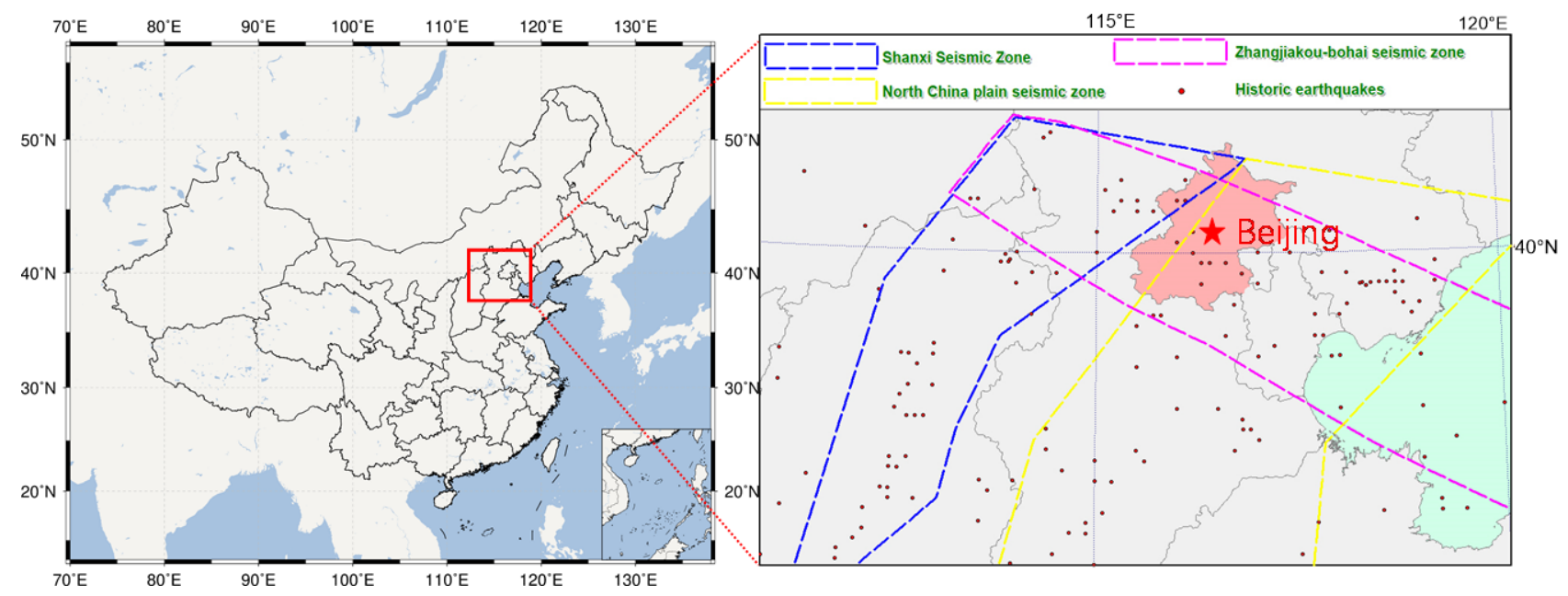

Figure 1. The geological environment and position of Beijing.

The Beijing area is located on the northwestern margin of the North China Plain, with the northeast-north-north-eastward fault as the main structure, and has developed a series of mantlebearing systems. Many scholars have conducted a lot of research on the activity and structure of the Beijing plain area and revealed the main tectonic framework in the Beijing area (e.g., Li et al.,
1989; Li et al.,1992; Xiang et al., 1993). Since the New Tertiary, various crust deformations have taken place due to the stress of the earth. It is directly reflected in the tectonic evolution and geomorphology. This crustal activity is closely related to the earthquake in the region. Since the Quaternary, under the influence of the tensile stress field near the north-west-southeast

* Corresponding author 
direction in this region, the extensional tectonic activity has acquired new features on the basis of inheritance. For example, some study found that the Yanhuai basin in the northeast and the Nankou-Shahe sag in the north west developed in the Jingxi uplift. The Beijing sag was reversed, the south coincided with the Daxing uplift, and the north developed the Quaternary of Shunyi in the east Depression (Wang et al., 1984). Based on the comprehensive analysis of the geological structure characteristics of the Beijing plain area, the Beijing plain area can be divided into seven "fault blocks", namely Machikou-Shahe, Xiaotangshan, Shunyi, Pinggu, Fengtai-Laiguangying, DaxingTongzhou. And Fangshan fault block (Zhao et al., 2015). Drilling technology was used to test the Nankou-Sunhe fault zone to study the multi-period features of the fault since the $60 \mathrm{ka}$ period, and the results show that the average vertical fault rate of the fault zone in each period was calculated (Zhang et al., 2007). Through the summary of the research results of the major active faults in the Beijing plain area, it is recognized that the HuangzhuangGaoliying fault is characterized by obvious sectional activities, and the largest northwest fault in the Beijing area at the time of the Nankou-Sunhe fault was identified, as well as Zhangjiakou Quaternary active faults in a wakeup table in the Bohai earthquake zone (Jiao et al., 2006). The fractures of the surface distribution nowadays occur in different geological periods. The results of the study indicate that the fractures in the Quaternary period are most closely related to the current seismic activity. The Quaternary active faults are the Huangzhuang-Goliying fault, the Babaoshan fault, the Shanqian fault at Nankou, the Sunhe fault at Nankou, and the Daxishan fault, the Gubeikou fault, and the Chenggezhuang fault in the northeastern part of Beijing. The north margin of the Yanzi Basin in the north-western region, the Zijingguan fault, and the south fault of the Niulula town in the south-eastern plain area (Lu et al., 2011).

Identifying the current horizontal and vertical crustal movement in Beijing is benefit for reveal the activity characteristics of the faults and is of great importance to reveal the risk of geological disasters in Beijing and to take the correct countermeasures.

The remainder of this work is structured as follows. The background is presented in Section 2. In Section 3 the related work is discussed. In Section 3. the data and the methodology we used is presented. The final experimental results are proposed in Section 4. Finally, the discussions and conclusions are presented in Section 5.

\section{BACKGROUND}

Steady contemporary vertical motion of the solid Earth is a consequence of ongoing geologic, volcanic, and geodynamic processes. Measurement of these motions reveals how the Earth behaves under various loads, provides information about the source and magnitude of forcing, and can be used to estimate the Earth's material and rheological properties (Hammond, 2016). (Colin, 2014) suggest that long-term and late-summer flexural uplift of the Coast Ranges reduce the effective normal stress resolved on the San Andreas Fault. This process brings the fault closer to failure, thereby providing a viable mechanism for observed seasonality in microseismicity at Parkfield and potentially affecting long-term seismicity rates for fault systems adjacent to the valley.

Due to its complex geological tectonic environment and its special geographical location in Beijing and its adjacent areas, the study of the crustal deformation characteristics in Beijing has started very early and a large amount of research has also been achieved. The measurement methods such as laser ranging, cross- fault level, and baseline are more traditional and effective means of monitoring the characteristics of vertical and horizontal deformation of the crust. A number of studies have used crossfault deformation observation data to make in-depth studies on the characteristics of crustal deformation in the Beijing area and have achieved rich results. These studies mainly focus on three aspects: the characteristics of fault activity, the relationship between fault activity and earthquake, and the division of block boundaries. Although the reliability of cross-fault level and baseline observation methods is relatively high, due to the need to invest a lot of manpower and material resources for repeated observations, it is difficult to obtain a larger range of overall movement characteristics.

GNSS (Global Navigation Satellite System) and InSAR (Interferometric Synthetic Aperture Radar) technologies are two new types of space-based earth observation techniques developed in recent years, and have great advantages in obtaining large-scale horizontal deformation and vertical deformation information. Among them, using the GNSS long-term observation can obtain the three-dimensional deformation time series of the station, and through the combination and solution of the observation network can obtain the horizontal and vertical deformation field information of the crust in the region, especially for obtaining the horizontal movement state of the crust has obvious advantages. Based on multiple GPS survey data from 1995 to 2005, the characteristics of the strain field in Beijing during this period were studied, and the areas with strong structural creep were revealed (Liangqian et al., 2006). Using the data of more than 280 GPS points in the metropolitan area from 1992 to 2004, a high-precision crustal deformation velocity field in this area was obtained. The slippage of the fault was calculated inversion, and the stress of the main active faults in the Capital Region was obtained. Strain field information (Xuejun et al., 2008).

InSAR (Interferometric Synthetic Aperture Radar) is a valuable technique for measuring surface deformation with high spatial resolution and high accuracy. It has been successfully applied to the monitoring of landslides, earthquake deformations, volcanic activities and urban subsidence as well as anthropogenic deformation caused by mining, oil, gas and groundwater extraction deformation with high spatial resolution and high accuracy (Hu et al., 2014). In recent years, more and more researchers have begun to use INSAR technology to observe and study the vertical movement in Beijing to analyze important deformation information such as land subsidence. Plenty of former research results have shown the significant land subsidence in Beijing and adjacent areas. L-band ALOS-2 INSAR method was used to investigate the accumulated deformation of Beijing area and to talk about the relationship between land subsidence and tectonic activity (Liang et al., 2013). Some research also investigated the long-term ground deformation in Beijing, using both ENVISAT-ASAR and ALOS PALSAR images and got the conclusion that the possible cause for the deformation is groundwater (Alex et al., 2014). Small Baseline InSAR technique was employed to process Envisat ASAR images and TerraSAR-X stripmap images collected from 2010 to 2013 to investigate land subsidence in the Beijing region and found some interesting relationships in terms of land subsidence with groundwater level, active faults, accumulated soft soil thickness and different aquifer types (Chen et al., 2014).

From the current research results, we can conclude that most of the research results indicate that the Beijing area is facing more serious land subsidence. Most research result shows the conclusion that the main reason for the subsidence is the Over- 
exploitation of groundwater. But the subsidence distribution shows different characteristics from some other cities with the same land subsidence problems. The subsidence distribution shows a clear relationship with main active faults in this area. It is important to find out the exact relationship between land subsidence, groundwater exploitation and the faults activity.

In this paper, we tried to find out this relationship using INSAR and GNSS technology with a comprehensive analysis with tectonic geology information. Based on the Sentinel TOPS and Radarsat-2 WIDE SAR images ranged from 2012-2017 to acquire crustal deformation in Beijing and adjacent areas. At the same time, take full advantage of the Continues GNSS observations in this area to acquire both horizontal and vertical deformation from 2006-2017. With these two type of deformation results, we carried out a Comprehensive analysis on the Crustal deformation characteristics and the mechanics to discuss the present crustal deformation type and relationship between Subsidence, Water exploitation and faults activity in Beijing areas.

\section{DATA AND METHODOLOGY}

In this paper, we used GPS data from 34 continuous-operation GNSS observatories covering Beijing and surrounding areas, and 55 SAR images range from 2012 to 2017 covering most of Beijing area to acquire the crustal deformation both in horizontal and vertical direction. Finally, we analysed and discussed the deformation characteristics of the present-day crust in Beijing in the horizontal and vertical directions. The time-series InSAR analysis were performed by the TSInSAR-AEM method (Li et al., 2009; Dai et al., 2016).

\subsection{GPS Data}

We used GPS data from continuous GNSS networks distributed throughout Beijing and adjacent areas, which all have stable monuments and provide daily receiver-independent exchange observation. We considered data available between years 2006.0 and 2017 from continuous networks of Beijing CORS and CMONOC GNSS networks. The distribution of the GNSS stations are shown as figure 2.

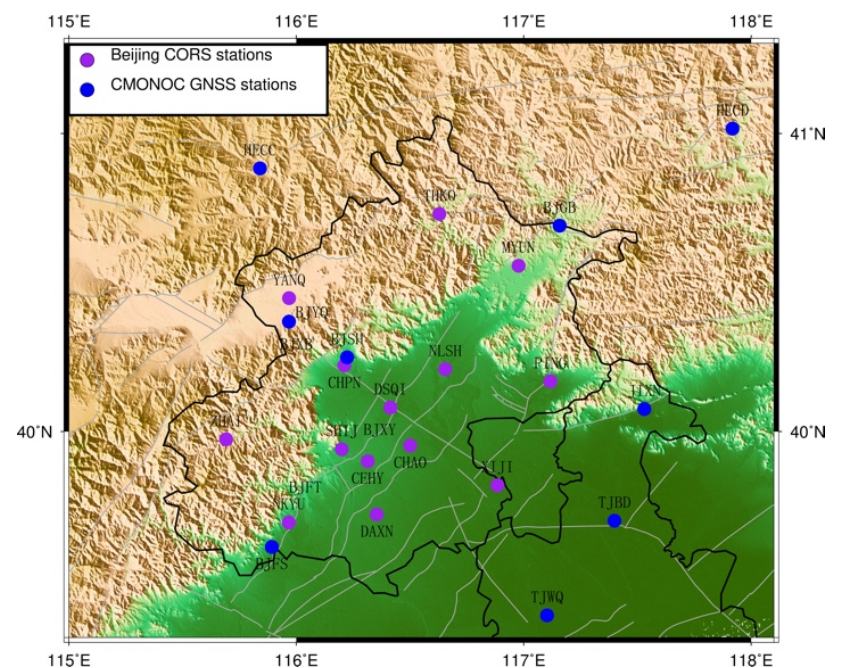

Figure 2. Distribution map of the GNSS stations used in this study.
In this paper, SAR images from two different sensors with different imaging geometries are obtained to show different period crustal deformation. These two type of SAR images are relatively Radarsat- 2 wide SAR images mode acquired from January 2012 to September 2015 and Sentinel-1 TOPS mode SAR images acquired from July 2015 to April 2017. The spatial and temporal baselines of those SAR images used in this study were shown in figure 3 and figure 4.

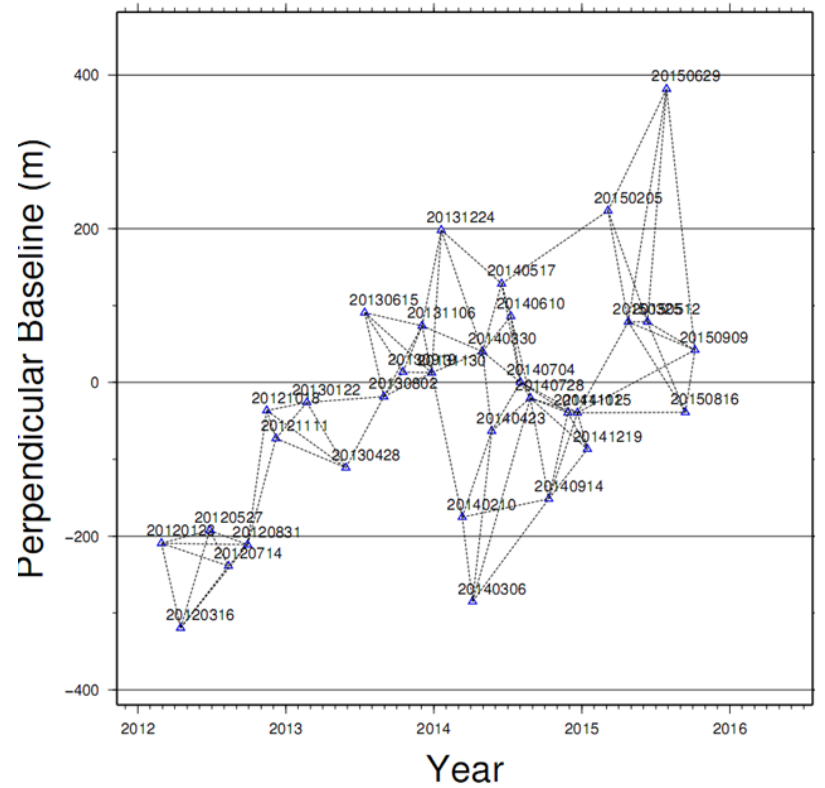

Figure 3. Spatial and temporal baselines of Radarsat-2 SAR images used in this study.

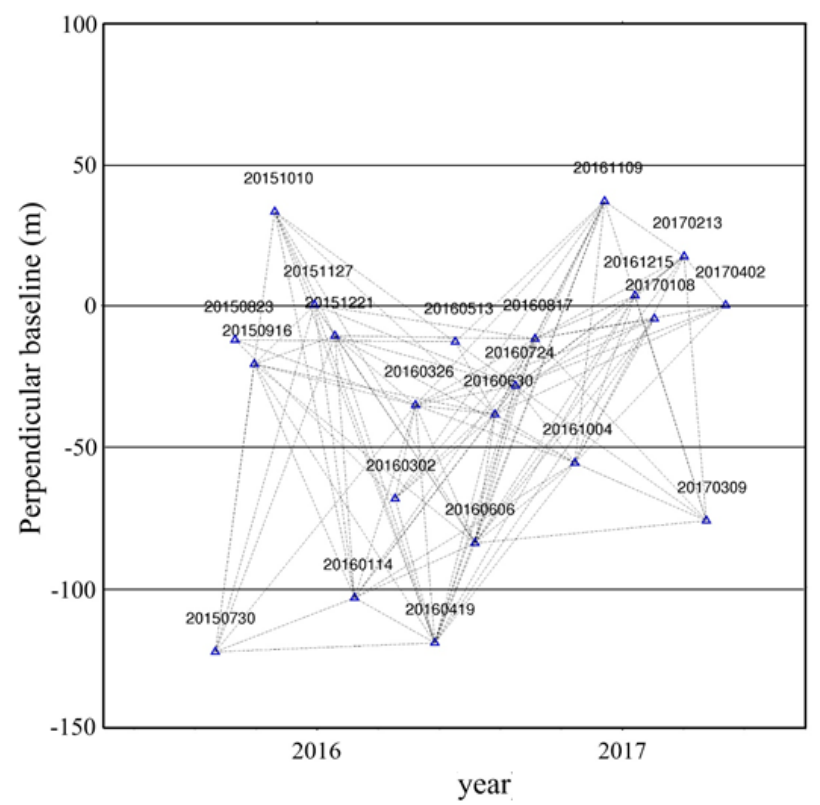

Figure 4. Spatial and temporal baselines of Sentinel TOPS SAR images used in this study.

\section{RESULTS}

Based on 34 continuous GNSS stations in and around Beijing, the 3D coordinates time series (North, East, Up) of these sites under the ITRF2008 framework were calculated and obtained. Hector time series analysis software was used to estimate the annual cycle, half-year cycle and noise model to estimate the accurate velocity of the site in north, east and up directions. The 
vertical crustal deformation velocity map we derive from the GPS observations are shown in figure 5.

In order to obtain the relative horizontal movement status of all the stations in the study area, we selected 27 relatively stable stations in the study area as the reference sites to estimate the whole movement trend of the study area under the global framework and deducted from all the stations. For the velocity in the north and east direction of the reference sites, we calculated a mean velocity and then be used as a block movement velocity. All the velocities of north and east direction were deducted by the block movement velocity, which was derived from the above method. Appling this method, the horizontal crustal deformation velocity resulted from GPS observation was derived and shown as figure 6 .

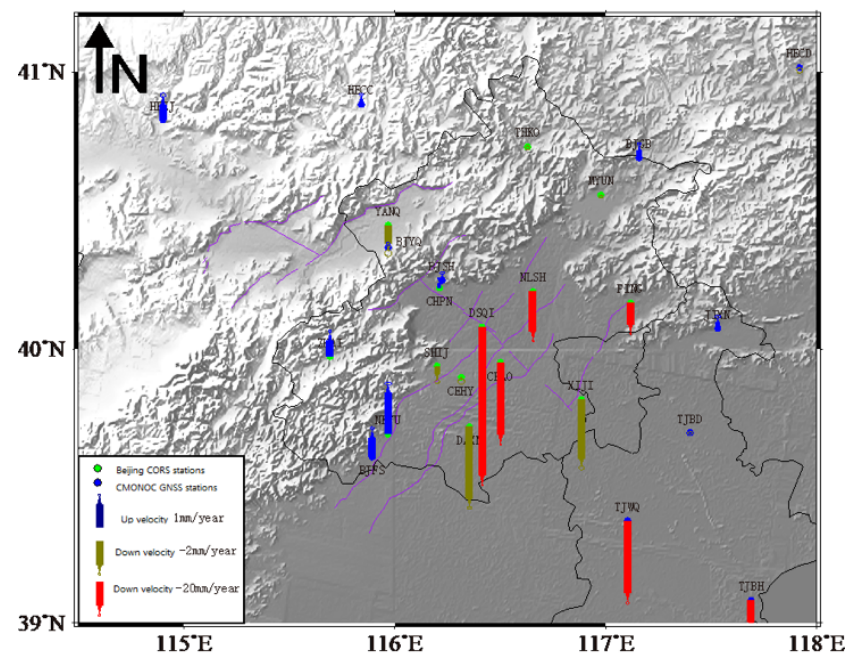

Figure 5. The Vertical crustal deformation velocity resulted from GPS observation.

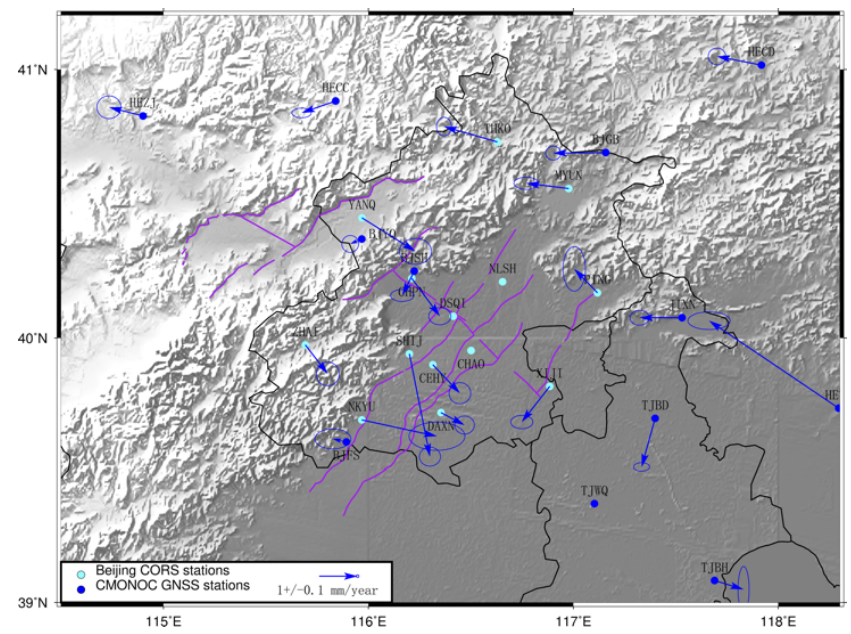

Figure 6. The horizontal crustal deformation velocity resulted from GPS observation.

The results of horizontal movement reveal the obvious left-lateral movement trend of the crustal in Beijing and surrounding areas, with the Nankou- Sunhe fault as the dividing line. The NankouSunhe fault is the main fault of the Zhangiiakou-Bohai fault zone, which is consistent with the L-strike-slip motion background of the Zhangjiakou-Bohai seismic zone.
Based on the new SBAS-INSAR time series analysis technology, we got the mean velocity field of crustal deformation along the line of sight (LOS) direction from 2012-2017 in Beijing area. The INSAR results are mainly based on two types of SAR images, which are Radarsat- 2 wide SAR images mode acquired from January 2012 to September 2015 and Sentinel-1 TOPS mode SAR images acquired from July 2015 to April 2017. In total 47 interferograms formed from 33 Radarsat-2 SAR images and 108 interferograms formed from 22 sentinel images were used in the calculation, provided sufficient observation for the accurate results.

The mean velocity field map of crustal deformation with higher spatial resolution from INSAR were derived and the results show that there is a slow uplift in the mountain area and a severe subsidence tendency in the plain area, which is consistent to the GNSS result. The results were shown separately from Radarsat2 (Figure 7) and Sentinel TOPS (Figure 8).

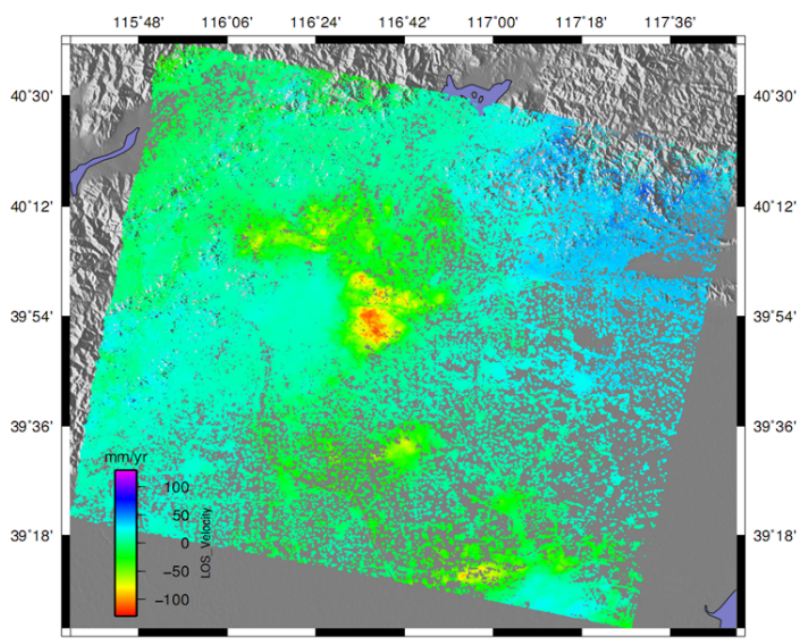

Figure 7. The mean velocity field of crustal deformation along the line of sight (LOS) direction from 2012-2015 derived from RADARSAT-2 WIDE mode SAR images.

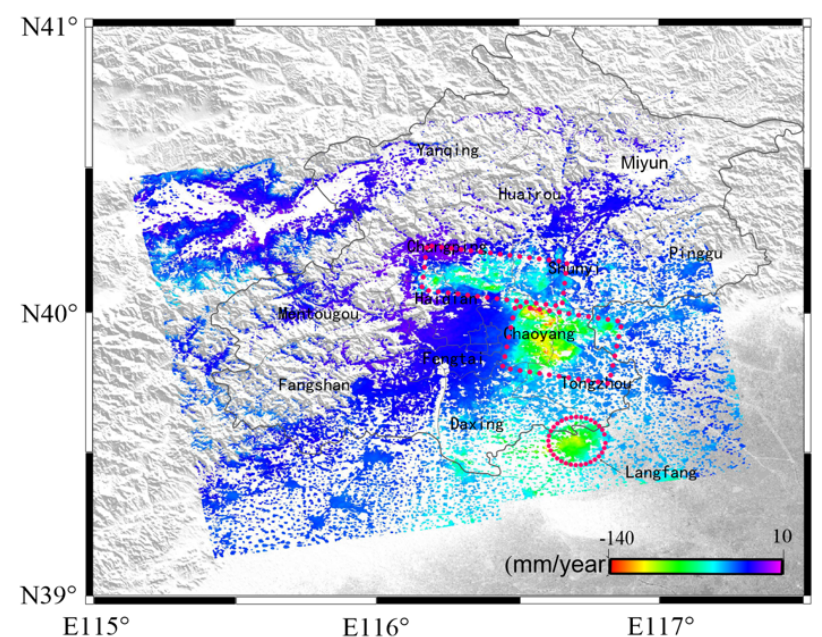

Figure 8 . The mean velocity field of crustal deformation along the line of sight (LOS) direction from 2015-2017 derived from Sentinel TOPS mode SAR images. 


\section{DISCUSSION AND CONCLUSION}

Geological structure data show that there are many Quaternary buried Depressions, such as Shunyi Depression, Huairou Depression, Pinggu Depression, Dachang Depression, Maikekou-Shahe Depression and Langfang Depression in the Beijing Plain. These Quaternary Depressions were closely related in space and genesis to buried active faults. Most of the depressions are controlled by NE or NW-trending buried active faults. According to the INSAR mean deformation velocity field map, we can find out the obviously phenomenon that the movement velocity in the main city (within the third ring) is relatively small, which indicates that the area is relatively stable, while there has a strip-shaped subsidence area in the southeast, and the subsidence bands are distributed in the northwest direction and distributed along the Nankou-Sunhe fault zone. From the perspective of spatial distribution, the subsidence area is obviously controlled by the Nankou-Sunhe fault, and part of the concentrated subsidence area is controlled by the NE-trending faults. Considering the distribution characteristics of Quaternary depression area, most of the present-day subsidence areas are closely related to the Quaternary depressions. However, some of the subsidence areas surpass the original ones. For example, the present subsidence area of the Machikou-sunhe depression is obviously southeastward extended through the XiaotangshanDongbeiwang fault but still under the control of the Huangzhuang-Gaoliying fault. This phenomenon shows that due to the influence of groundwater over exploitation and other factors, some areas have developed further on the basis of the Quaternary depression. However, their development areas are still controlled by active faults.

In conclusion, the Continues GNSS results reveal that the crust in Beijing shows a significant left-lateral trend movement in the horizontal direction, while the vertical direction shows a gentle rise in the mountainous region and a significant subsidence in the plain area. The INSAR results shows a detailed subsidence area and the deformation characteristics were analysed considering the fault activity. The foundation of geological structure dominates the subsiding in the Beijing Plain. The exploitation of groundwater exacerbates the level of subsidence and has new development. The active faults controlled the development of the subsiding in present days.

The results in this paper reveals the characteristics of the crustal deformation in the horizontal and vertical directions in Beijing and the mechanism of the occurrence and development of the subsidence in combination with the tectonic settings. This study has a good guiding significance for understanding the formation mechanism of ground subsidence in the background plains and taking reasonable countermeasures, and ascertain the present state of crustal movement in Beijing and its neighbouring areas. It provides basic data for in-depth understanding of the risk of geological disasters in the area and also provides a guarantee for the construction of an indicator system for resilient cities in Beijing.

\section{ACKNOWLEDGEMENT}

This research is funded by the project of the science for earthquake resilience (No. XH18001Y) and the project of Three issues of monitoring, forecasting and scientific research (No. CEA-JC/3JH-160101) from China Earthquake Administration.

\section{REFERENCES}

Amos, C.B., Audet, P., Hammond, W.C., Bürgmann, R., Johanson, I.A., Blewitt, G., 2014. Uplift and seismicity driven by groundwater depletion in central California. Nature 509, 483.

Chen, M., Tomás, R., Li, Z., Motagh, M., Li, T., Hu, L., Gong, H., Li, X., Yu, J., Gong, X., 2016. Imaging Land Subsidence Induced by Groundwater Extraction in Beijing (China) Using Satellite Radar Interferometry. Remote Sensing 8, 468.

Dai, K., Li, Z., Tomás, R., Liu, G., Yu, B., Wang, X., Cheng, H., Chen, J., Stockamp, J., 2016. Monitoring activity at the Daguangbao mega-landslide (China) using Sentinel-1 TOPS time series interferometry. Remote Sensing of Environment 186, 501-513.

Guo, L., Li, Y., Huang, L., Hu, X., Buo, W., 2006. Characteristics of strain field variation in beijing area. Journal of Geodesy and Geodynamics 3, 008.

Hammond, W.C., Blewitt, G., Kreemer, C., 2016. GPS Imaging of vertical land motion in California and Nevada: Implications for Sierra Nevada uplift. Journal of Geophysical Research: Solid Earth 121, 7681-7703.

Hu, B., Wang, H.-S., Sun, Y.-L., Hou, J.-G., Liang, J., 2014. Long-Term Land Subsidence Monitoring of Beijing (China) Using the Small Baseline Subset (SBAS) Technique. Remote Sensing 6, 3648-3661.

Li, H., 1989. On relationships between the characteristic of neotectonic movement and earthquake in Beijing area. Journal of Beijing Normal University (Natural Science) 4, 016.

Li, Z., Fielding, E.J., Cross, P., 2009. Integration of INSAR timeseries analysis and watervapor correction for mapping postseismic motion after the 2003 Bam(Iran) earthquake. IEEE Trans. Geosci. Remote Sens. 47 (9), 3220-3230.

Jiao, Q., Qiu, Z., 2006. Research progress of major active faults in Beijing plain area. Crustal Structure and Crustal Stress, The Institute of Crustal Dynamics, Chinese State Seismological Bureau, Earthquake Press, Beijing 18, 72-84.

Liang, F., Sun, J., Shen, Z., Xu, X., 2013. Accumulated crustal deformation and its characteristics in Beijing and surrounding regions in 2007-2010 from L-band InSAR. Earthquake 33, 4354.

Lu, M., Huan, B., Liu, T., Shao, Y., Kou, J., Fang, Z., Zhang, J., Yu, H., 2011. Analysis on Earthquake Reflecting Ability of Cross-fault Observation Data and Monitoring Capability of Sites in the Capital Area of China. Earthquake 3, 121-134.

Ng, A.H.-M., Ge, L., Li, X., Zhang, K., 2012. Monitoring ground deformation in Beijing, China with persistent scatterer SAR interferometry. Journal of Geodesy 86, 375-392.

Wang, R., Huang, L., 1984. Horizontal deformation and its geotectonic implication in the beijing area. Seismology and Geology 4, 001.

Xiang, H., Fang, Z., Zhang, W., Li, R., Jia, S., 1995. joint profile survey of active features for the late quaternary subsurface faults in beijing plain region. journal of seismological research. journal of seismological research 1 . 
Xu, J., Wang, L.-m., Fang, Z.-j., 1992. Preliminary analysis of the tectonic activities of Babaoshan and Huangzhuang-Gaoliying faults in Beijing area. North China Earthquake Sciences 10, 1-11.

Yong, Z., Xiang-min, C., Jiming, W., 2015. The division of "small blocks" of structure in Beijing plain and a discussion on the activity of micro block in Quaternary period. Geology in China 42, 1876-1884.

Zhang, S., Wang, D., Liu, X., 2007. Sequence stratigraphy study of Late Quaternary activities of Nankou-Sunhe fault in its northern segment, Beijing. Seismology and Geology 29, 729743. 